\title{
Contesting heritage: language, legitimacy, and schooling at a weekend Japanese-language school in the United States
}

\author{
Neriko Musha Doerr ${ }^{\mathrm{a} *}$ and Kiri Lee ${ }^{\mathrm{b}}$ \\ ${ }^{a}$ Brookdale Community College, New Jersey, USA, ${ }^{b}$ Lehigh University, Pennsylvania, USA \\ (Received 3 June 2008; final version received received 6 November 2008)
}

\begin{abstract}
Researchers have shown that the maintenance of a minority language has positive effects on the minority students' view of self, educational attainment, and career opportunities (Cho 2000; Wright and Taylor 1995). In the research for this article, however, we found that such a focus on the effects of heritage-language education on the students is of limited usefulness in analyzing the complex processes of heritage-language education. Based on our ethnographic study at a weekend Japanese-language school in the United States, we illustrate contestations among administrators, students, and parents regarding the legitimacy of two types of Japanese heritage-language program and diverse subjectivities of heritage-language students that are causes and effects of such contestations. We suggest approaching heritage-language education not merely as an effort to enhance awareness of one's heritage or an instruction in language but also as a schooling process in which legitimacy of the knowledge and ways to achieve it are contested in the process of students and parents navigating what school offers, the students' linguistic proficiencies, their future educational prospects, and their diasporic subjectivities.
\end{abstract}

Keywords: heritage languages; identity; discourse; ethnography; language learning; sociocultural theory

\section{Introduction}

Researchers have shown that the maintenance of a minority language ${ }^{1}$ has positive effects on the minority students' view of self, educational attainment, and career opportunities (Cho 2000; Tse 1997; Wright and Taylor 1995). This has been a main premise of heritagelanguage education. For example, Cho (2000) shows how individuals who are proficient in their heritage language have strong ethnic identification and confidence, which positively affect their social relationships with other heritage speakers of the language. Fishman $(2001,95)$ also states that '.. promoting heritage-language proficiency ... will not only give us more individuals proficient in these languages, it will also dignify our country's heritage-language communities and the cultural and religious values that their languages represent'. These studies focus on the position of heritage-language learners within the political economy and cultural politics of particular nation-states (Borland 2005; Fishman 2001; Hornberger 2005; Mercurio and Scarino 2005; Tavares 2000) and the multiplicity of contexts in which heritage learners learn to make sense of and situate themselves flexibly (Creese et al. 2006; Curdt-Christiansen 2006, 2008; He 2006).

While such research tends to treat the heritage-language learners' link to heritage as given, other research focuses on the relationship among heritage-language learners and

*Corresponding author. Email: nm22@cornell.edu 
analyze the nuanced processes by which heritage-language learners relate themselves to the heritage (Jo 2001; Martinez 2003; Valdes 1981; also see Hornberger and Wang 2008). Much of these studies focus on micro-level resistance, negotiation, and conformity to the standardization processes. This article adds to such studies an analysis of contestation among administrators, parents, and students around standardization by the homeland government. Based on a five-month-long ethnographic fieldwork at a weekend Japanese-language school in the United States in 2007, this article reframes heritage-language education as a schooling process in which the legitimacy of what constitutes knowledge/heritage is contested and examines the processes by which students and parents relate themselves to what heritagelanguage school offers, see legitimacy in it, and develop their subjectivities.

As part of a four-year project at Jackson Japanese Language School (JJLS for short; all the names in this article are aliases) to investigate how different types of classes influence students' subjectivities, this article examines subjectivities of students and parents developed around two tracks of heritage-language education - one that follows a curriculum prescribed by the Japanese government for students in Japan and the other that does not and contestations among school administrators, students, and parents regarding the legitimacy of the latter track. Because the experience of Japanese-language education for most 'Japanese'2 students and parents have been through a government-prescribed curriculum, a program that does not follow such a curriculum forced the students and parents to rethink what 'learning Japanese' means, which was manifested in the ways they did or did not legitimize the program. This article draws on an analytical framework in education that views the contestation of the legitimacy of knowledge as part of a schooling process (Apple and Weis 1983; Olneck 2000) and analyzes struggles of an administrator, students, and parents to define what constitutes a legitimate 'Japanese' language, reflecting their diverse linguistic proficiency, personal histories, educational aspirations, and subjectivities.

In what follows, we introduce Japanese heritage-language schools in the United States and the types of Japanese-language instructions offered, describe research context, introduce perceptions of the two tracks of heritage-language programs at our research site by administrators, students, and parents, and analyze contestations around what constitutes a legitimate way to learn 'Japanese' language highlighted by the juxtaposition of these two tracks within a school.

\section{Japanese heritage-language schools in the United States}

In the United States, as of May 2008, there are $86^{3}$ weekend Japanese-language schools called hoshuko (supplementary school). They are community-based schools that provide 'Japanese' children in the 1st to 9th grade (ages six to 15) who go to a local school or an international school during the week with part of the education they would have received in Japanese compulsory education, using the Japanese government-prescribed curriculum and the Japanese government-certified textbooks. The main subject matter is kokugo (language arts of Japanese national language). Some schools offer mathematics, science, and social studies in addition to kokugo. ${ }^{4}$ They often include preschool/kindergarten and high school programs, as well. The Japanese Ministry of Education, Culture, Sports, Science and Technology (MEXT) deploys some teachers and subsidizes hoshuko with more than 100 'Japanese' students. This is the Japanese government's effort to provide children of Japanese citizens overseas with access to part of its compulsory education. This effort is due to Article 26 of the Japanese Constitution, which guarantees free compulsory education for Japanese children between the ages of six and $15 . .^{5}$ 
Although 'Japanese' children go to hoshuko, they may have various backgrounds in terms of the length of stay in the United States based on their parents' situations. Some are in the United States for three to five years; some stay longer than five years without a definite plan to return to Japan; and some are permanent residents. The difference in their background shows in their language abilities and cultural familiarity. Since hoshuko usually targets the children with 'native' competency in Japanese who are in the United States for a short term, those who have less than 'native' competency are often marginalized, and sometimes shy away from using/learning the language around 'native speakers' of the language. In order to accommodate such students who often do not plan to return to Japan to live and do not need to follow the kokugo curriculum, programs for keishogo (Japanese-as-a-heritage-language) education have been established since the 1990s.

There are two aspects of the difference between kokugo and keishogo education. First, while kokugo education presupposes full attainment of daily use of the target language or what Cummins (2001) calls 'Basic Interpersonal Communicative Skills (BICS)', keishogo may not. Based on this assumption, kokugo education provides education in academic Japanese or what Cummins (2001) calls 'Cognitive Academic Language Proficiency (CALP)'. ${ }^{6}$ Kokugo education is set rigidly to each grade level, including the kanji (Chinese characters) to be learned at each grade. Thus, lagging behind in the content expected at a particular grade level creates the situation of students unable to keep up. ${ }^{7}$

In contrast, keishogo education aims at attainment of CALP but not in the time frame designated in kokugo education as its students have considerable individual differences in BICS (Kondo-Brown 2003). ${ }^{8}$

Secondly, kokugo and keishogo education have different political connotations, as the former is strongly linked to Japan's nation-building. Based on the model of one nation, one language, the Meiji administration in the nineteenth century chose a linguistic variety used by educated people in its capital city, Tokyo, as a standard language, and imposed it on its citizens as the only legitimate one through compulsory kokugo education in an effort to create a homogeneous 'Japanese' nation (Lee 1996; Yasuda 2003). Thus, the Japanese government prescribes kokugo education. In fact, in discussing the dichotomy between standard Japanese used in kokugo and various dialects of the Japanese language, Yasuda (1999) argues that there is a hierarchical relationship in the Japanese school system where a school teaches standard Japanese through kokugo to students who may speak other dialect, thus creating the sense that standard language used in kokugo is the legitimate one and everything else is not.

On the other hand, the keishogo curriculum is outside this government prescription and is developed by teachers and administrators in each school. Although researchers have various opinions as to what keishogo is, ${ }^{9}$ to the general public the language instruction offered in hoshuko is considered kokugo education for 'native speakers' and thus 'Japanese', and that offered in a program independent of Japanese government prescription is considered keishogo education for 'heritage-language speakers' and thus 'Japanese-Americans'. In discussing the programs at JJLS, we contrast kokugo education within hoshuko and keishogo education in Jackson course. Our position is that kokugo education in hoshuko programs and keishogo education in the Jackson course are two tracks - nationalized and local, respectively - of heritage-language education, following the definition of a heritagelanguage learner in the United States by Valdes $(2001,38)$ : 'A language student who is raised in a home where a non-English language is spoken, who speaks or at least understands the language, and who is to some degree bilingual in that language and in English'. 


\section{Research context}

\section{Jackson Japanese language school}

Jackson Japanese Language School is a weekend Japanese-language school that offers both kokugo and keishogo education with a special focus on students who live in the United States on a permanent basis. JJLS is located in the suburb of a major metropolitan area in the northeastern United States and caters to students from preschool (three years old) to adults who wish to learn Japanese language. JJLS was founded in 1980, and received the first principal sent by MEXT in 1989. JJLS is a private non-profit organization financed by tuitions, the MEXT (50\% of the rent and 50\% of hoshuko teachers' salary), and donation from local businesses. JJLS is overseen by the board of trustees. The board members are usually educators and business people in the local community. New board members are nominated by the nominating committee in the Board and approved by the board of trustees.

JJLS consists of two education divisions. The first division is hoshuko program. The second division houses all other programs: preschool, kindergarten, high school, Japaneseas-Foreign-Language (JFL), and Jackson course (see Figure 1). The Jackson course is the first program at JJLS to explicitly teach the keishogo curriculum as an alternative to the hoshuko program, although its high school program has been offering two tracks since 1995 (one for Japanese college-bound students, and the other for US college-bound students). Such an arrangement is uncommon in hoshuko in the United States.

The school meets 42 Sundays a year from 1:00 pm to 4:20 pm. It also offers optional math classes between 11:50 am and 12:35 pm every Sunday and an optional current affairs class for middle school students between 4:30 pm and 5:15 pm every other Sunday.

\begin{tabular}{|c|c|c|c|}
\hline \multicolumn{3}{|l|}{ Grade } & \\
\hline PreK & & \multirow{2}{*}{$\begin{array}{l}\text { Pre-school program } \\
3-5 \text { years old }\end{array}$} & \\
\hline \multicolumn{2}{|l|}{$\mathrm{K}$} & & \\
\hline 1 & \multirow{6}{*}{$\begin{array}{l}\text { Hoshuko } \\
\text { Elementary school } \\
\text { Grade 1-6 }\end{array}$} & & \multirow{8}{*}{$\begin{array}{l}\text { JFL program } \\
\text { Grade } 1-8\end{array}$} \\
\hline 2 & & Jackson course & \\
\hline 3 & & Level 2 & \\
\hline 4 & & Level 3 & \\
\hline 5 & & (Grade 2-6) & \\
\hline 6 & & & \\
\hline 7 & \multirow{3}{*}{$\begin{array}{l}\text { Middle school } \\
\text { Grade 7-9 }\end{array}$} & Level 4 & \\
\hline 8 & & (Grade 7-9) & \\
\hline 9 & & & \multirow{6}{*}{$\begin{array}{l}\text { JFL program } \\
\text { Grade } 9-12 \\
\text { and adult }\end{array}$} \\
\hline & & & \\
\hline 10 & & \multirow{3}{*}{$\begin{array}{l}\text { High school } \\
\text { program } \\
\text { Grade } 10-12\end{array}$} & \\
\hline 11 & & & \\
\hline \multicolumn{2}{|l|}{12} & & \\
\hline Adult & & & \\
\hline
\end{tabular}

Figure 1. Structure of JJLS. The arrows show the possible advancement to the upper grades and the possible transfer to a different program within the school. The transfer between the programs is determined on discussions among a pertinent student, his/her parents, and a pertinent teacher/administrator. 
JJLS caters to a heterogeneous student body that can be roughly categorized by their intended length of stay as (1) chuzai (short-term residence) group, who live in the United States temporarily for three to five years due to a parent's intra-company transfer, (2) chokitaizai (long-term residence) group, who plan to stay in the United States for more than five years with an undetermined plan to return to Japan by a parent's possible intra-company transfer, and (3) eiju (permanent residence) group, who have no plans of going to Japan to live. ${ }^{10}$ In the third group, it is often the case that one of the parent's first language is not Japanese.

For chuzai students, Japanese tended to be their first language until they came to the United States. They consider themselves as a 'native speaker' of Japanese. For some chokitaizai students, English may have become their most used language and Japanese is used only in the limited situation. For eiju students who were usually born and are being raised in the United States, it is more likely that English is their first language and Japanese their second language.

Despite this diversity in students' linguistic competence and experiences with Japanese, all of them used to attend hoshuko until 2004, which carries out the kokugo curriculum designed for Japanese 'native speakers' of the same age in Japan, covering one week worth of language arts materials in one Sunday afternoon. Consequently, for some students, it became difficult to meet its expectations. In order to accommodate such students, JJLS has offered several optional classes with the keishogo curriculum supplemental to attending the hoshuko class for 1st to 9th-grade children since 2002. The Jackson course is the first coherent program with the keishogo curriculum serving as an alternative to the hoshuko class.

Jackson course was established in 2004 for mostly eiju students whose purposes for studying Japanese language did not fit the curriculum and expectation in the hoshuko class. It has three multi-age classes. ${ }^{11}$ It uses Japanese as the medium of instruction and, in contrast to hoshuko program, covers various subject matters. Linguistically, Jackson course targets the students who have or almost have attained the age-appropriate BICS, but are having a difficulty shifting BICS to CALP in the hoshuko program. Thus, one of the goals of Jackson course is an attainment of CALP, corresponding roughly to the attainment level of CALP in kokugo education, but with different approaches. For example, Jackson course's curriculum is designed to build on to students' diverse bilingual experiences rather than imposing curriculum designed for monolingual students living in Japan. Jackson course also takes a holistic approach, e.g., attainment of the Japanese language is explored through social science, science, language arts, and music. In contrast, in the hoshuko program, its attainment is, in principle, solely through the prescribed kokugo textbooks. Thus, Jackson course's not rigidly following kokugo curriculum does not translate into a 'slower' class or class for students with lower linguistic proficiency. However, there were various interpretations of the Jackson course, including viewing it as a class for dropouts.

Because the hoshuko program had been the only choice for the students and parents, when the alternative curriculum was presented, some of the students had to rethink how they wish to learn Japanese. This article investigates meaning-making practices of students and parents about programs offered at JJLS and how that involves reanalyzing their purpose of Japanese language study as well as their subjectivities.

\section{Fieldwork method}

The ethnographic method allows us to understand the processes and results of learning from individuals' perspectives and how they are situated in their personal histories as well 
as in the wider cultural politics. It gives voice to individuals' viewpoints that may otherwise not be heard and reveal processes in which their subjectivities are negotiated and contested.

Clifford (1988, 41-2) points out that it is "necessary to conceive of ethnography not as the experience and interpretation of a circumscribed "other" reality, but rather as a constructive negotiation involving at least two, and usually more, conscious, politically significant subjects ... There is no neutral standpoint in the power-laden field of discursive positionings, in a shifting matrix of relationships'. Being researchers involves us in a regime of power/knowledge that constitutes power relations between those who create and manage the knowledge and those who become the object of knowledge (Foucault 1972; also, see Marcus 1998).

To make matters more complex, the authors are involved in the school community at JJLS in multiple ways, being part of the community before starting the fieldwork. ${ }^{12}$ Doerr is a substitute teacher at JJLS, but does not substitute for the classes with students participating in our research. Lee is an administrator of JJLS. We suspect that these subject positions of ours allowed us to have the trust of the participating teachers and parents, thus making it easier to gain permission to do research than those from outside the school community. However, Lee's position of authority did, we suspect, give pressure for some people to participate in our research. Both Doerr and Lee have children enrolled in grades different from the target students of our research at JJLS. This subject position puts us closer to other parents, sharing similar concerns about children, school, and working together as parent volunteers. For students, our position as parents lessened the impact of our presence as researchers, but increased their concern regarding their privacy; we assured them from time to time that the confidentiality was strictly enforced. In these ways, these multiple positions not only provided us various entry points but also created some constraints on our research.

The data discussed in this study were collected from February to June 2007, the first five months of a four-year project. We have chosen students in the 6th grade (ages 11 and 12) hoshuko-class and the Level 3 (ages nine to 12) of Jackson course in the academic year of April 2006 to March 2007 as target groups to follow for four years. We obtained written consent forms from all the students and parents who agreed to participate in this project. School administrators and teachers involved in the project also signed written consent forms. Strict confidentiality was promised. There were 17 students in the 6th grade hoshuko-class in the 2006-2007 academic year. Roughly a half of them were chuzai and choki-taizai and the other half were eiju students. In the Level-3 Jackson-course class, there were five students - four eiju and one choki-taizai Korean student. ${ }^{13}$ When the new Japanese academic year began in April 2007, there were fourteen 7th-grade hoshuko students ${ }^{14}$ and six Level-4 Jackson-course students. ${ }^{15}$

We interviewed students, parents, and teachers. Of 17 6th-grade hoshuko students, we interviewed nine students and eight of their parents during this research period. We also interviewed all five students in Level-3 Jackson course and their parents. We interviewed two teachers, one that taught 6th grade in hoshuko and one that taught the Level 3 of Jackson course. Interviews were carried out before or after the class at a school library, lobby of the building, or an empty classroom. We took notes and audio-recorded the interview upon permission. We gave the interviewees a choice of language (English or Japanese) as a medium of interview. Interviews done in Japanese were translated into English for this article by the authors. Interviews lasted from about 15 minutes to three hours. All interviews, except for two at which both of us were present, were done by one of us. However, for consistency, we use the term 'we' throughout this article. We speak both English and Japanese fluently and research was conducted mainly in Japanese. 
We also carried out participant observation in classrooms. We observed five sessions of hoshuko classes and Jackson-course classes each (recorded by audio-recorder and field notes) from February to June 2007. This article focuses on the interview results as they explicitly portray the individual's opinions and perceptions of hoshuko and Jackson course, although participant observation helps us grasp different expressions of the same individual's opinions and perceptions that may differ depending on the context.

\section{Perceptions of keishogo education: an administrator, students, and parents}

In order to illustrate the ways in which students and parents viewed the Jackson course, we introduce in this section two kinds of accounts. First, we introduce the experience of the principal of the second education division recounted by Lee, one of the authors of this article. Second, we introduce in-depth interviews of four eiju students and their parents.

As we mentioned earlier, we have multiple positions in conducting this research at JJLC. This affected Lee in particular because Lee is the head of the second education division, and has been leading the development of Jackson course since 2004 when she succeeded her predecessor who established Jackson course. Her position as an administrator enabled us to gain an in-depth understanding of personal investments and struggles behind the process of building Jackson course, and it helped formulate this article as a whole, which may have not been possible by interviews only. At the same time, she admits that sometimes she had to control her emotions when portraying some of the difficulties in the process.

\section{Administrator's account: development of Jackson course}

In the first year of the Jackson course, Lee encountered three factors that made some eiju parents reluctant to transfer their children to Jackson course. The first was parents' perceptions about themselves and their children. Most of the 'Japanese' parents at JJLS felt keishogo education is for 'Japanese-Americans', not for their 'Japanese' children. Most of them were born and raised in Japan and now are living in the United States. Having received kokugo education themselves, many parents viewed that kokugo is a legitimate education for 'Japanese' and they wanted their children to learn kokugo at JJLS. One mother commented to Lee that she does not (want to) believe that her children's Japanese is 'keishogo'. Another mother told her that, if it wesn't for the kokugo education in hoshuko, it would not be worth sending her sons to JJLS. Therefore, around the time when Jackson course was planned and implemented, there was a definite atmosphere that kokugo education in hoshuko was one and only legitimate way of giving the 'Japanese' education.

The second factor was a perception of the Jackson course. Since the teacher and three out of seven students of the first Jackson course were recruited from the JFL program, parents felt it was more like another JFL class. But the fact was that these three children were eiju students with some knowledge of Japanese language but who were placed in the JFL class because they did not have any kokugo education prior to attending JJLS. Lee and her predecessor judged that they would benefit from the curriculum of the Jackson course rather than the JFL program because of their level of BICS. Moreover, the other four students who transferred to Jackson course from hoshuko were considered as linguistically insufficient to keep up with the curriculum in hoshuko. As a result, the new class in Jackson course was perceived as a class for dropouts. Some parents commented to Lee: 'My children will grow up here but I hesitate to switch them to Jackson course because it is labeled as a class for dropouts'. 
The third factor was a configuration problem. Jackson course only offered one class when it started. Thus, the parents who were interested in Jackson course were uncertain about where their children would be in a couple of years when they only saw one multi-age class, in contrast to the established hoshuko program which offered 1st to 9th grade. Some parents decided to take a 'wait and see' attitude.

Since then, Lee had held an information session every year and explained about Jackson course, i.e., it is for the children who do not plan to go through the Japanese education system in Japan, and therefore, it does not follow the kokugo curriculum; it uses textbooks approved by the MEXT but as resources for further language activities; and the class is solely conducted in Japanese. The enrollment of Jackson course increased from seven in the 1 st year to 19 in 2007-8. Lee feels that more parents have started understanding the suitability of the Jackson course for their children.

\section{Cases of four students (not) joining Jackson course}

While chuzai and choki-taizai students took it for granted to attend hoshuko, some eiju students often entertained the idea of choosing between hoshuko and Jackson course. We introduce below the interview results of four eiju students regarding how they decided to join or not join Jackson course, coupled with their parents' accounts. They exhibit that this process involved each student's understanding of both the difference between hoshuko and Jackson course and what she/he wants in terms of language and subjectivity. Note that we give transcript of students' interviews particularly relevant to the main focus of our research, and embed other quotes in a narrative summary of their interviews.

\section{Sasha: a Jackson-course old-timer}

Sasha started JJLS in preschool. She moved from hoshuko to Jackson course in 2004 when she entered 3rd grade. In April 2007, she moved from Level-3 to Level-4 Jackson course. She chose English as a medium of interview.

Sasha considers herself as 'American' because she was born in the United States, but also 'Asian' because her parents are Asian and she could speak Chinese and Japanese besides English. Sasha told us that her mother is 'Chinese/Malaysian' and her father is 'Japanese'. Sasha said she attends JJLS in order to learn how to write and speak in Japanese so that she can go around in Japan by herself and interact with her grandparents there. Sasha also has been going to Chinese-language school on Friday nights for about eight years.

She remembered hoshuko was hard.

Author:

Sasha:

Author:

Sasha:

Author:

Sasha:

Author:

Sasha:
What do you think about hoshuko class?...

Actually, I think theirs is a bit harder and it sort of challenges you more and I couldn't exactly keep up and that's why my dad put me in the Jackson course so that I can enjoy it better.

Uh huh.

So that I can keep up and stuff.

Do you have a same image about it still? ...

Yeah. I still remember some parts of it.

Okay.

Sometimes I didn't understand what teachers were saying when they called on me and I am like one of the people who didn't know a lot of the kanji. 
Sasha's father, Yoshihiko, came to the United States from Japan in 1984 to attend a business school. He recalls, 'I was not comfortable in the Japanese society'. He feels that he is in-between 'Japanese' and 'American'. He feels his children are 'American, or really, Asian American', he said.

He decided to send his children to JJLS because, he explained, 'I did not have time to teach them Japanese myself'. Seeing his children struggled with the workload in the hoshuko class, he moved them to the Jackson course, because, he said, 'I just wanted them to be able to communicate in Japanese with me'. He found the Jackson course 'wonderful' if it were not for the Jackson course, he added, 'my children would have stopped coming to JJLS'. He described the Jackson course as 'less demanding' as the teacher teaches at a level appropriate to students' and classmates having 'similar background and goals' in learning Japanese. 'It is great that Sasha is in the multicultural [not just Japanese] environment, as Sasha has much in common with them', he added.

\section{Mayumi: moved from Hoshuko to Jackson course after 6th grade}

Mayumi was one of three 6th-grade students who moved from hoshuko to Jackson course when Level-4 class was first offered in April 2007. Mayumi started coming to JJLS in preschool. The interview was done in English one month before she moved to Jackson course.

Mayumi said she is 'half Japanese' and 'half Russian'. Her mother's ethnicity, attending Japanese-language school, visiting Japan often, and having kimono all make her 'Japanese', she said. According to her, what makes one 'Japanese' is parentage, not language, but she added that she feels she is more 'Japanese' than 'Russian' because she speaks the language.

Mayumi began JJLS because her mother wanted her to speak Japanese to her grandparents. Mayumi now enjoys learning about her 'own culture' and wants to be bilingual. Mayumi described her experience in hoshuko with diverse students as follows: 'It is fastpaced because we have to do a week-worth of work in one day. So, they don't take time to explain and it is hard for me to understand because I'm not advanced in Japanese ... Some find it just right speed because they came from Japan and are here for a short time. Japanese is their native language and it comes naturally to them. For me, Japanese is my second language and it takes a while to think in Japanese . . I cannot understand things sometimes. It is frustrating. When I give up, it becomes boring. In regular school, I know all the language and I can form questions better.' 16

Mayumi used to think that 'Jackson course is like JFL but with Japanese as a medium of instruction'. Her mother introduced the idea that she move there. Before she was in 6th grade, she always felt 'why change now' because she came all the way in hoshuko. But, graduating from the elementary school after 6th grade was an opportunity to think about changing a course. Mayumi thought, 'teachers in Jackson course might explain things better' and went to the trial class. There, she could understand everything the teacher said. Mayumi decided to move to Jackson course from 7 th grade.

During our observation in both hoshuko and Jackson-course classes, there was a striking difference in the way Mayumi behaved in class. In hoshuko class, she was very quiet, although she gave correct answers whenever teacher called on her. It looked as though the talkative chuzai students who dominated casual conversation marginalized her. In Jackson course, however, Mayumi was very active and talkative, initiating discussions and even teasing the teacher.

Mayumi's mother, Naoko, came to the United States in the 1980s in order to attend a university. She said, 'I disliked the expectation in Japan that everyone has to act the same 
way'. She married 'a [Russian-] American' and stayed in the United States. Naoko said, 'I might have forgotten about Japan if Mayumi was not born'.

Naoko feels that coming to JJLS and learning Japanese language and culture helped Mayumi realize that she is 'Japanese'. However, Naoko found the homework to be too much and kanji too difficult. Naoko said 'the diversity of students in hoshuko [some chuzai and some eiju] is natural'. In the past, however, she said, 'Some chuzai students misbehaved, letting the steam off their frustration in English environment at regular school. Some of them even teased mistakes made by some eiju students. The problem ended when such chuzai students went back to Japan'.

When the Jackson course began, Naoko suggested Mayumi to join. But, Mayumi felt that the 'Jackson course was for dropouts' and did not want to join, Naoko reported. The trial class Mayumi attended recently changed her view, Naoko explained. In Naoko's views, 'the Jackson course prepares students for an Advanced Placement Japanese course in the US high schools' and uses 'real' Japanese with an experienced teacher.

\section{Anne: staying in Hoshuko}

Anne had come to JJLS since preschool. She went to hoshuko throughout elementary school and stayed in hoshuko when she entered 7th grade. She chose Japanese as a medium of interview, but we shifted to English at times. Anne said her father is 'Japanese' and mother is 'American'. She said she herself is 'mixture of Japanese and American'.

What she wants from the Japanese-language school is to learn Japanese language and culture so that she can say 'I can speak Japanese' and 'I have two cultures', she said. She further commented, 'When I go somewhere and say I am Japanese ... if I didn't go to Japanese-language school, it feels strange. It's strange to say I cannot speak Japanese but I am Japanese'.

While she liked school events such as field day, she did not like homework and kanji in hoshuko class, which she found difficult. She was critical about chuzai students, who, she felt, had arrogant attitude because they could speak Japanese very well. However, Anne never thought about joining Jackson course because she felt it would be too easy for her.
Author:
Have you ever thought about moving to Jackson course? ...
Anne:
No, I haven't.
Author:
You haven't. Why?
Anne:
Because to go to Japanese-language school is ... to go to school and speak Japanese, so, because I feel people mix Japanese and English in Jackson course, it is a little too easy, I feel.

Lois and Takeshi, Anne's parents, met in Japan and came to the United States in 1995 because Takeshi decided to attend a business school here. Lois said she is 'American', born in the United States, but lived in Japan for several years. Anne's father, Takeshi, said he is 'Japanese', but wonders if he is not as much 'Japanese' as he thinks when he compares himself to chuzai parents who just arrived from Japan.

Both Lois and Takeshi wanted their children to be bilingual and had been sending them to JJLS. Lois and Takeshi felt that 'chuzai students use Japanese-language school as a place to let off steam from the stress of regular school', thus 'acting up in the classroom', as Naoko also pointed out. Takeshi never thought about sending Anne to the Jackson course because, according to him, 'we wanted her to be $100 \%$ bilingual'. He felt that the Jackson course has 'a different goal'. 


\section{Martin: starting in Jackson course}

Martin began attending JJLS when he was in 4th grade in September 2005 because Martin's parents thought he should learn reading and writing in Japanese. The interview was done in Japanese.

Martin's father is 'American' and his mother is 'Japanese', he said. Martin said he is 'Japanese' because he was born in Japan, although he came to the United States when he was one-year old. Coming to JJLS and learning Japanese makes him feel more 'Japanese' because, for him, what makes a person 'Japanese' is being born in Japan and speaking Japanese, he explained. When he plays with his American friends, however, he feels that he is American, he said.

Martin had attended schools in Japan for at least four weeks in summer whenever he and his family went there in past several years. Martin joined Jackson course from the beginning at JJLS. It is difficult to join hoshuko unless the student has been learning kokugo since 1 st grade because of the way certain content, especially kanji, is assigned to each grade. Martin was the top student in Level-3 class, actively participating in class discussion, and seeming to be comfortable with class content and materials.

Martin expressed his view of hoshuko and Jackson course as follows:

Author: If you compare Jackson course and hoshuko, what's the difference in the image you have about them? The image of hoshuko and that of Jackson course ...

Martin: Hoshuko seems a little more 'Japanese' and a little more difficult.

Author: It seems difficult. How about Jackson course?

Martin: Um, a little easier.

Martin's mother, Satoko, came to the United States 'to learn English'. She met her husband in the United States and got married. She said 'my children would live as American, .. but I am Japanese because my parents are Japanese and I was born in Japan'. She added, 'sending my children to JJLS and making my own Japanese friends there makes me feel closer to Japan'.

She likes the Jackson course because 'Martin can have friends with a similar background to speak Japanese with'. There is 'no pressure because it is more about exposing the children to Japanese language than test scores'. She feels that the Jackson course deepened Martin's confidence, especially because he can visualize his progress through 'learning more kanji and compare his Japanese to other students of his age'. She is happy that teachers use teaching materials besides kokugo textbooks.

Satoko did not realize that Jackson course was considered 'a drop-out class' until her children began attending. But, 'I feel that such perception is changing', she said.

\section{Diverse ways to (not) belong to Jackson course}

The account by Lee, the administrator, and the interviews of students and parents show contestations of meaning as to what Jackson course is about. Such contestations were caused by the very juxtaposition of the original hoshuko program and the newly created alternative Jackson-course program. Before the Jackson course was offered, the students who felt out of place in hoshuko often left JJLS and quit learning Japanese or sought private tutoring. Because the decision to leave JJLS included other factors - conflict in schedules, distance of commuting, etc. - and because they often left the JJLS school community, there was little occasions for discussion with other parents and students regarding their views on Japanese-language education and subjectivities. 
However, when the students and parents were given an alternative way to learn Japanese within the same school (i.e., the Jackson course), the factors affecting their decision-making were narrowed down to the difference in programs: the legitimacy in curriculum and teaching methods as well as the student body. With a similar amount of commitment in time and efforts, parents and students were forced to examine their reasons for membership in hoshuko or the Jackson course more closely, including whether the child will become a 'legitimate Japanese-language speaker'. Staying in the same school and continuing to socialize within the JJLS community, parents of the Jackson-course students were often presented with occasions to discuss and legitimize their choice of leaving hoshuko. Through such discussions, meaning of the Jackson course was contested.

In an effort to change the perception that the Jackson course is a class for dropouts, Lee, an administrator, has consciously informed parents that the Jackson course has a different idea of proficiency, and that proficiency can be attained outside the kokugo curriculum. Despite this, some students and parents have kept the perception that the Jackson course is an 'easy class' for dropouts, and its offering as something illegitimate compared to what hoshuko offers. However, some students and parents started to view the Jackson course as less vigorous but suiting their needs.

These perceptions that students and parents developed were based not only on the administrator's explanation but also on their own experiences, i.e., the pace and explanations the Jackson-course curriculum offers (Sasha, Sasha's father, Mayumi, Martin, and Martin's mother); observation of types of students who attend the Jackson course (Mayumi, Sasha's father, Martin, and Martin's mother); hearing others' comments on the class (Anne); its relevance to the education in the US context (Mayumi's mother); subjectivities as 'Japanese' (Mayumi, Anne, and Martin); and subjectivities as bilingual individuals (Mayumi, Anne, and Anne's father). In order to analyze diverse ways students and parents perceived Jackson course, we categorize eiju students, the main target of Jackson course, into three groups.

First group is what we call 'rescued students'. The 'rescued students' are those who found it difficult linguistically to keep up with the hoshuko class, and thus were 'rescued' by the existence of Jackson course. Sasha belongs to this group. Both Sasha and her father viewed Jackson course to be easier than hoshuko, by reducing an array of different teaching styles and goals that the Jackson course offers into mere difference in 'difficulty'. However, they viewed Jackson course to be matching needs of Sasha's whom both identified as (Asian)-American. 'Rescued students' are the type of students that exhibit 'language shyness', as described by Krashen (1998). Students such as Sasha, and Mayumi and Anne to a certain degree, develop a sense of threat around more linguistically proficient 'native speakers' of the language, which can lead to shying away from using/learning the language. In order to save such students, Krashen suggests creating a separate class for them. Jackson course at JJLS provided such a different domain where these students did not have to feel shy about using the language.

The second group is what we call 'potential traversers'. They are those who could keep up with the kokugo curriculum, although they found it difficult. Mayumi and Anne belong to this group. Their difficulty arose in two aspects: covering a fixed amount of material in the fixed time frame in hoshuko, and learning alongside chuzai students who are more fluent in Japanese. Cramming a-week-worth of kokugo curriculum in one Sunday afternoon, the teachers in hoshuko did not have time to explain things in depth to 'potential traversers'. In relation to chuzai students, Mayumi had a clear understanding why her Japanese is not as good as theirs: Japanese is her second language.

'Potential traversers' (had) viewed Jackson course to be for dropouts (Mayumi, according to her mother) and students who need some English to understand the class content 
(Anne). They did not recognize any legitimacy in what Jackson course offers in comparison to what hoshuko offers. However, Mayumi changed her view later and recognized Jackson course as a legitimate class in which the teacher takes time to explain things better than in hoshuko class because there is no pressure to cover all the kokugo curriculum. Thus, for Mayumi, an imagined community of speakers (Anderson 1991; Pavlenko 2007) of Jackson course transformed from dropouts to those who learn Japanese outside the prescription of kokugo while keeping the same linguistic quality. In due course, Mayumi redefined herself as a 'Japanese speaker' different from hoshuko students, but a 'Japanese speaker' nonetheless. Mayumi's mother viewed Jackson course to be legitimate viewing that it offers preparation for AP Japanese and 'real' Japanese.

In contrast, Anne stayed with hoshuko, despite her uncomfortableness with chuzai students. To say 'I can speak Japanese' and 'I am Japanese', Anne felt she had to survive in the kokugo education in hoshuko along with more fluent chuzai students. For her, moving to Jackson course would be to drop out because she believed that Jackson course mixed English and Japanese. Norton (2000, 10-1) states that, 'when language learners speak, they are not only exchanging information with target language speakers, but they are constantly organizing and reorganizing a sense of who they are and how they relate to the social world. Thus an investment in the target language is also an investment in a learner's own identity'. Thus, Anne's choice of Japanese for interviews, in contrast to Mayumi, illuminates this 'investment' of hers, although she had to switch to English occasionally for communicative purposes during the interview. Her father thought Jackson-course students would not be ' $100 \%$ bilingual', indicating the full competence of 'Japanese' is nurtured only in hoshuko. Anne and her father viewed that Jackson course does not offer legitimate knowledge of 'Japanese'. For them, 'being Japanese', 'speaking Japanese', and kokugo education in hoshuko were all connected. This connection reflects the discourse of Japan's nation-building which links the standardized linguistic competence to the nationhood, whose tool has been compulsory kokugo education (Yasuda 2003).

The difference between Mayumi and Anne is their views on what constitutes 'knowing Japanese'. Mayumi said, even though competence in Japanese is not essential, she would feel more 'Japanese' because she knows the language. Later when she chose to attend the Jackson course, knowing 'Japanese' for her was not necessarily tied to the governmentprescribed grade-specific kokugo curriculum. For Anne, in contrast, the Japanese language outside kokugo education in hoshuko was not good enough, especially if they use English in the classroom. In short, Mayumi and Anne imagined a community of 'Japanese-language speakers', and by extension, of 'legitimate Japanese' differently. Their imaginings reflect their own subjectivities as members of that community.

The difference between 'rescued students' and 'potential traverser' is the level of language proficiency: the former's proficiency gave them no choice but to join Jackson course, while the latter's proficiency gave them a choice, in which subjectivity more than language proficiency mattered.

The third group is what we call 'system outsiders'. They (and their parents) chose Jackson course because they have never received kokugo education and did not see a need to do so. That is, they are outside the system of kokugo education. Martin is such a student. He enjoyed Jackson course as 'Japanese', while acknowledging that hoshuko students are 'more Japanese'. Martin's mother signed him up for Jackson course because it teaches Japanese outside the kokugo education, although he could have kept up in hoshuko class linguistically. Although Martin viewed the difference between hoshuko and Jackson course to be the difficulty of the content (Jackson course to be easier) and chuzai students more 
'Japanese', he and his mother viewed Jackson course to be offering legitimate Japanese instructions.

As shown above, the ways students and their parents perceive Jackson course and their subjectivities in relation to it are complex and cannot be analyzed adequately by the existing analytical framework of heritage-language education that focuses on the learner's position in the mainstream society or language acquisition processes. While Krashen (1998) describes the situation of students like Sasha, Mayumi, and Anne in relation to those with 'native-like' proficiency, his suggestions for creating a separate class needs to be situated in the understanding of schooling processes. Due to the students' perceptions toward Jackson course, a domain Krashen advocates, Jackson course worked for Sasha who struggled linguistically in hoshuko, but it did not work for Anne who could follow hoshuko program with some struggle and viewed staying in hoshuko as an important part of her being 'Japanese'. ${ }^{17}$ What mattered to students like Anne was whether or not she could recognize what is offered in Jackson course as legitimate, which reflects on her subjectivity as a 'Japanese'.

Educational researchers argue that the school conveys general understandings of what knowledge is considered legitimate and how certain difference among students should be noted and made consequential (Bourdieu and Passeron 1977; Varenne and McDermott 1999). Thus, school is often a site of contestation regarding which knowledge should be considered legitimate (Apple and Weis 1983; Giroux 2001; Jacob and Jordan 1993; Olneck 2000). Contestation among school administrator (Lee), students, and parents regarding the position of Jackson course we analyzed in this article can be understood as a contestation about the legitimacy of keishogo curriculum in Jackson course as the knowledge of Japanese language.

The contestation of legitimacy of Jackson course needs to be viewed in relation to already established and legitimized hoshuko class. In the homeland, kokugo curriculum has been made legitimate by the Japanese government for a century. Therefore, for many years, offering kokugo curriculum in hoshuko program and its legitimacy were never questioned no matter how diverse the students' backgrounds may have been. By offering an alternative to hoshuko and striving to become legitimate, Jackson course challenged the hegemony of kokugo education in hoshuko as the only legitimate one. Moreover, in the context of 'heritage' language education, the contestation regarding what constitutes legitimate 'Japanese' knowledge is linked to the contestation regarding what constitutes a 'Japanese person'.

\section{Conclusion}

Researchers on heritage-language education focus on the positions and subjectivities of heritage-language learners, describing benefits of maintaining a minority language for them (Fishman 2001; Valdes 2001). However, the case at JJLS exhibits complex processes of heritage-language schooling that call for a different kind of analytical tool. When the school offered two tracks of heritage-language classes, for some students, joining the Jackson course was due to their linguistic ability, such as shown in Sasha's case, but for others, it was more than their linguistic ability shown in the contrast between Mayumi and Anne, and despite linguistic ability as shown in Martin's case. What they considered as 'legitimate knowledge' - which was being contested among administrators, students, and parents - influenced their decisions to join hoshuko or the Jackson course. This article suggests that, in order to analyze this complexity, we need to approach heritage-language education not merely as an effort to enhance awareness of one's heritage or an instruction in 
language but also as a schooling process, in which what constitutes legitimate knowledge and legitimate ways of attaining it are contested.

\section{Notes}

1. According to Baker $(2006,215)$, heritage-language education is categorized as maintenance bilingual education.

2. We use quotation marks for 'Japanese' when what constitutes Japanese is ambiguous and/or contested.

3. From http://www.joes.or.jp/g-kaigai/gaikoku03.htm.

4. From http://www.mext.go.jp/a_menu/shotou/clarinet/002/002.htm.

5. 'Kaigai-de manabu nihon-no kodomotachi - Wagakuni-no genjyo' (Japanese Children Overseas - Present Situation in Our Country), a publication of the MEXT, January 2008.

6. The main purpose of education at hoshuko is attainment of CALP in Japanese (see Sato 1997 and the publication of the MEXT in note 5), and this is emphasized in the information session for hoshuko program held annually by the administrators at JJLS.

7. Detailed discussion will be shown later in the article on how such students position themselves at school.

8. When no BICS was expected of students, it is called Nihongo education (Japanese-as-a-foreignlanguage education).

9. For different views regarding the treatments on kokugo education offered in hoshuko, see. e.g., Chinen and Tucker (2005); Douglas (2006), among others.

10. There is one more group of students, who learn Japanese as a foreign language at JJLS. However, we do not include this group here because they are not relevant to this study. They attend JFL class whose medium of instruction is English.

11. Level 2 is for 2 nd and 3rd graders, Level 3 for 4 th through 6 th graders, and Level 4 for 7 th to 9th graders. There is no Level 1.

12. Our being part of the school community prior to the fieldwork makes us "native anthropologists." However, the concept has been criticized for its reliance on a simplistic insider/outsider dichotomy and its dismissal of the 'multiple planes of identification' of any individuals (Narayan 1993, 676; also, see Reed-Danahay 1997).

13. The Korean student moved from a JFL course due to scheduling conflict.

14. One hoshuko student left school, another hoshuko student returned to Japan, and three hoshuko students moved to the Level 4 of Jackson course. Two new students joined hoshuko class.

15. Three out of five Level-3 Jackson-course students moved to Level 4. Three students from hoshuko joined them.

16. This quote comes from the fieldnotes. Because of a technical mishap, we could not record this interview.

17. From our interviews and classroom observations, we noticed that students' language proficiency in Japanese couldn't be measured by how they became bilingual (i.e., whether they are 'simultaneous' bilinguals or 'successive' bilinguals). For example, some simultaneous bilinguals were as proficient in Japanese as successive bilinguals who were monolingual Japanese speakers first.

\section{References}

Anderson, B. 1991. Imagined communities. London: Verso.

Apple, M., and L. Weis. 1983. Ideology and practice in schooling: A political and conceptual introduction. In Ideology and practice in schooling. Ed. M. Apple and L. Weis, pp. 3-33, Philadelphia, PA: Temple University Press.

Baker, C. 2006. Foundations of bilingual education and bilingualism. 4th ed. Clevedon, UK: Multilingual Matters.

Borland, H. 2005. Heritage languages and community identity building: The case of a language of lesser status. The International Journal of Bilingual Education and Bilingualism 8, no. 2\&3: $109-23$.

Bourdieu, P., and J.-C. Passeron. 1977. Reproduction in education, society and culture. London: Sage. 
Chinen, K., and R. Tucker. 2005. Heritage language development: Understanding the roles of ethnic identity and Saturday school participation. Heritage Language Journal 3, no. 1: 27-59.

Cho, G. 2000. The role of heritage language in social interactions and relationships: Reflection from a language minority group. Bilingual Research Journal 24, no. 4: 333-48.

Clifford, J. 1988. The predicament of culture: Twentieth-century ethnography, lierature, and art. Cambridge, MA: Harvard University Press.

Creese, A., A. Bhatt, N. Bhojani, and P. Martin. 2006. Multicultural, heritage and learner identities in complementary schools. Language and Education 20, no. 1: 23-43.

Cummins, J. 2001 (1996). Negotiating identities: Education for empowerment in a diverse society. Los Angeles, CA: Association for Bilingual Education.

Curdt-Christiansen, X.L. 2006. Teaching and learning Chinese: Heritage language classroom discoruse in Montreal. Language, Culture and Curriculum. 19, no. 2: 189-207.

Curdt-Christiansen, X.L. 2008. Reading the world through words: Cultural themes in heritage Chinese language textbooks. Language and Education 22, no. 2: 95-113.

Douglas, M. 2006. Pedagogical theories and approaches to teach young learners of Japanese as a heritage language. Heritage Language Journal 3, no. 1: 60-82.

Fishman, J.A. 2001. 300-plus years of heritage language education in the United States. In Heritage languages in America. Ed. J.K. Peyton, D.A. Ranard, and S. McGinnis, pp. 81-97. McHenry, IL: Center for Applied Linguistics and Delta Systems.

Foucault, M. 1972. Archaeology of knowledge. London: Harper Colophon.

Giroux, H. 2001. Theory and resistance in education. Westport, CT: Bergin \& Garvey.

He, A.W. 2006. Toward an identity theory of the development of Chinese as a heritage language. Heritage Language Journal 4, no. 1: 1-28.

Hornberger, N.H. 2005. Introduction: Heritage/community language education: Us and Australian perspectives. The International Journal of Bilingual Education and Bilingualism 8, no. 2\&3: $101-8$.

Hornberger, N.H., and S.C. Wang. 2008. Who are our heritage langauge learners? Identity and biliteracy in heritage language education in the United States. In Heritage language education: A new field emerging. Ed. D.M. Brinton, O. Kagan, and S. Bauckus, pp. 3-38. New York: Routledge.

Hye-Young, J. 2001. 'Heritage' language learning and ethnic identity: Korean Americans' struggle with language authorities. Language, Culture and Curriculum 14: 26-41.

Jacob, E., and C. Jordan. 1993. Understanding minority education: Framing the issues. In Minority education: Anthropological perspectives. Ed. E. Jacob and C. Jordan, pp. 3-14. Norwood, NJ: Ablex.

Kondo-Brown, K. 2003. Heritage language instruction for post-secondary students from immigrant backgrounds. Heritage Language Journal 1, no. 1: 1-25.

Krashen, S. 1998. Language shyness and heritage language development. In Heritage language development. Ed. S.D. Krashen, L. Tse, and J. McQuillan, pp. 41-49. Culver City, CA: Language Education Associates.

Lee, Y. 1996. Ideology called "Kokugo": Cognition of language in modern Japan. Tokyo: Iwanami Shoten. (In Japanese.)

Marcus, G. 1998. Ethnography through thick and thin. Princeton, NJ: Princeton University Press.

Martinez, G.A. 2003. Classroom-based dialect awareness in heritage language bilingualism. 8, no. 2\&3: 145-59.

Norton, B. 2000. Identity and language learning: Gender, ethnicity and educational change. Harlow, GB: Pearson Education.

Narayan, K. 1993. How native is a "Native" anthropologist? American Anthropologist 95, no. 3: 671-86.

Olneck, M. 2000. Can multicultural education change what counts as cultural capital? American Educational Research Journal 37, no. 2: 317-48.

Pavlenko, A., and B. Norton. 2007. Imagined communities, identity, and English langauge learning. In International handbook of English language teaching. Ed. J. Cummins and C. Davison, pp. 668-80. New York: Springer.

Reed-Danahay, and E. Deborah. 1997. Introduction. In Auto/ethnography: Rewriting the self and the social. Ed. D.E. Reed-Danahay, pp. 1-17, Oxford: Berg.

Sato, G. 1997. Reconstruction of education of oversea/returnee children: From the perspective of cross-cultural education. Tokyo: Tamagawa University Press. (In Japanese.) 
Tavares, A. (Tony) J. 2000. From heritage to international languages: Globalism and western Canadian trends in heritage language education. Canadian Ethnic Studies Journal March 22, 1-13.

Tse, L. 1997. Affecting affect: The impact of ethnic language programs on student attitudes. Canadian Modern Langauge Review 53, no. 4: 705-28.

Valdes, G. 1981. Pedagogical implications of teaching Spanish to the Spanish-speaking in the United States. In Teaching Spanish to the hispanic bilingual: Issues, aims, and methods. Ed. G. Valdes, A.G. Lozano, and R. Garcia-Moya, pp. 3-20. New York: Teachers College Press.

Valdes, G. 2001. Heritage language students: Profiles and possibilities. In Heritage languages in America. Ed. J.K. Peyton, D.A. Ranard, and S. McGinnis, pp. 37-77. McHenry, IL: Center for Applied Linguistics and Delta Systems.

Wright, S.C., and D.M. Taylor. 1995. Identity and the language of the classroom: Investigating the impact of heritage versus second language instruction on personal and collective self-esteem. Journal of Educational Psychology, 87, no. 2: 241-52.

Yasuda, T. 1999. Between Kokugo and dialects. Kyoto, Japan: Jinbun shoin. (In Japanese.)

Yasuda, T. 2003. Perspectives towards post- “Japanese language.” Tokyo: Sangensha. (In Japanese.)

Varenne, H., and R. McDermott. 1999. Successful failure: The school America builds. Boulder, CO: Westview Press. 
Copyright of Language \& Education: An International Journal is the property of Multilingual Matters and its content may not be copied or emailed to multiple sites or posted to a listserv without the copyright holder's express written permission. However, users may print, download, or email articles for individual use. 